\title{
Aplikasi Transportasi Online GO-JEK Bentuk dari Konstruksi Sosial Teknologi dalam Media Baru
}

\author{
${ }^{1}$ Henry Brown Nathalia, ${ }^{2}$ Irwansyah \\ ${ }^{1}$ Magister Ilmu Komunikasi Universitas Mercu Buana, Jl.Meruya Selatan No. 1, Meruya Selatan, \\ Kembangan, Jakarta Barat 11650 \\ ${ }^{2}$ Departemen Ilmu Komunikasi Fisip UI, Universitas Indonesia, Depok, Jawa Barat 16424

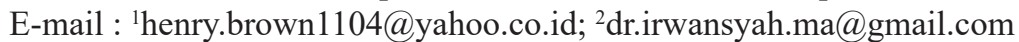

\begin{abstract}
Abstrak: Teknologi merupakan sesuatu hal yang tidak dapat dipisahkan dari kehidupan masyarakat modern sekarang ini. Teknologi hadir untuk membantu manusia dalam menjalankan aktivitas sehari-hari. Apakah manusia sebagai pencipta teknologi, atau teknologi membentuk manusia yang sedemikian rupa? Pertanyaan tersebut coba dijawab oleh Teori Kontruksi Sosial Teknologi, teori ini berpandangan bahwa manusia yang menentukan teknologi. Kontruksi sosial teknologi merupakan kondisi dimana masyarakat membutuhkan dan membuat teknologi karena didasari oleh kebutuhan sosialnya. Artinya, manusia dan teknologi tak akan pernah bisa dipisahkan. Manusia akan terus membutuhkan teknologi dan berinovasi menciptakan teknologi baru untuk memudahkan segala aktivitas kehidupan manusia. Hadirnya aplikasi transportasi online, sebagai bentuk contoh kongkrit dari implementasi kontruksi sosial teknologi dalam media baru, dimana aplikasi transpotasi online seperti GO-JEK ini diciptakan sebagai solusi bagi masyarakat untuk mengatasi permasalahan kemacetan jalan dan kebutuhan akan transportasi yang lebih mudah, cepat dan efisien.
\end{abstract}

Kata Kunci: teknologi, konstruksi sosial teknologi, media baru, aplikasi transportasi online

\begin{abstract}
Technology is something that can't be separated from the life of modern societies today. Technology is present to help man to run their daily activities. Are humans as creators of technology, or technology that shapes humans in such a way? This question tried to answer by the Social Construction of Technology theory, this theory views that man determine technology. Social Construction of Technology is condition in which the society needed and make technology because of their social necessity. It means, human and technology can not be separated. People will continue to need technology and innovate to create new technologies to make their daily activities easier. the presence of online transportation apps, as a concrete example of the implementation of social construction technologies in new media, online transpotation applications such as GO-JEK were created as a solution for the society to resolve traffic jam problems and their needs for easier transportation that fast and efficient.
\end{abstract}

Keywords: technology, social construction technology, new media, online transport application 


\section{PENDAHULUAN}

Teknologi merupakan sesuatu hal yang akrab dengan kehidupan masyarakat modern sekarang ini. Teknologi sudah menyatu dalam kehidupan manusia dimana teknologi memberikan dampak dan pengaruh disegala aspek kehidupan manusia. Teknologi lahir dari pemikiran manusia yang berusaha untuk mempermudah kegiatan-kegiatannya yang kemudian diterapkan dalam kehidupan.

Kini teknologi telah berkembang pesat dan semakin canggih seiring dengan perkembangan zaman. Kemajuan teknologi adalah sesuatu yang tidak bisa dihindari dalam kehidupan ini, karena kemajuan teknologi akan berjalan sesuai dengan kemajuan ilmu pengetahuan. Setiap inovasi diciptakan untuk memberikan manfaat positif bagi kehidupan manusia. Teknologi juga memberikan banyak kemudahan, serta sebagai cara baru dalam melakukan aktivitas manusia. Manusia juga sudah menikmati banyak manfaat yang dibawa oleh inovasi-inovasi teknologi terutama kemunculan internet diera 90 an memberikan banyak kemudahankemudahan bagi kehidupan manusia. Dimana dengan internet membuat kehidupan manusia tidak dibatasi lagi oleh ruang dan waktu, dan membuat kehidupan manusia lebih efektif dan efisien.

Internet atau era digitalisasi mendorong pesatnya kemajuan teknologi khususnya teknologi informasi dan komunikasi. Teknologi Informasi dan komunikasi terus lahir dengan inovasiinovasi baru untuk menjawab kebutuhan masyarakat. Sejak kemunculan smartphone (ponsel pintar), sebagai produk dari hasil kemajuan teknologi informasi dan komunikasi. smartphone memberikan dampak yang luar biasa bagi sosial budaya bagi masyarakat. smartphone menjadi benda yang terpenting dalam menunjang aktivitas sehari-hari manusia, smartphone tidak hanya sebagai alat komunikasi, tetapi sebagai media yang dapat membantu untuk kebutuhan sehari-hari baik sebagi pusat informasi, alat untuk kerja, alat untuk pembayaran, dan berbagai fungsi lainnya melalui aplikasi-aplikasi yang di unduh. Berbicara mengenai aplikasi, aplikasi adalah penggunaan dalam suatu perangkat komputer, instruksi (instructiom) atau pernyataan (statement) yang disusun hingga sedemikian rupa komputer dapat memproses masukan (input) menjadi keluaran (output) (Jogiyanto, 2001) . Aplikasi yang diperuntukan perangkat smartphone atau gadget dikenal dengan istilah aplikasi mobile (mobile application). Aplikasi Mobile adalah perangkat lunak yang berjalan pada perangkat mobile seperti smartphone atau tablet PC. Aplikasi mobile juga dikenal sebagai aplikasi yang dapat diunduh dan memiliki fungsi tertentu sehingga menambah fungsionalitas dari perangkat mobile itu sendiri. Untuk mendapatkan mobile application yang diinginkan, user dapat mengunduhnya melalui situs tertentu sesuai dengan sistem operasi yang dimiliki. Google Play dan iTunes merupakan beberapa contoh dari situs yang menyediakan beragam aplikasi bagi pengguna Android dan iOS untuk mengunduh aplikasi yang diinginkan.

Berbagai aplikasi dibuat sebagai solusi yang hadir untuk membantu aktivitas masyarakat sehari-hari dengan menfaatkan teknologi. Dewasa ini terdapat terobosan terbaru, yakni inovasi transportasi berbasis mobile application yang didukung oleh teknologi komunikasi melalui smartphone. Transportasi berbasis aplikasi mobile ini merupakan penggabungan dari segi jasa transportasi dan teknologi komunikasi. Hadirmya GoJek, Grab, dibuat untuk menjadi solusi dari kebutuhan masyarakat terhadap transportasi. Kebutuhan masyarakat akan 
transportasi yang cepat, efisien akan selalu tinggi terutama di kota besar. Dimana tingkat mobilitas masyarakatnya cukup tinggi, mengandalkan kendaraan umum saja tidaklah cukup. Aplikasi transportasi online dibuat untuk mengatasi kebutuhan masyarakat akan transportasi yang lebih mudah, cepat dan efisien.

Kemampuan manusia menentukan perkembangan teknologi menjelaskan bahwa manusia memiliki kuasa terhadap teknologi. Manusia yang menentukan teknologi akan seperti apa atau bermanfaat untuk apa. Inilah yang disebut konstruksi sosial terhadap teknologi. Perkembangan teknologi terbentuk karena adanya kebutuhan dari masyarakat. Menurut Neil Postman teknologi diciptakan dengan 2 tujuan yaitu "to solve specific and urgent problems of physical life' and 'to serve the symbolic world of art, politics, myth, ritual, and religion" (untuk memecahkan masalah-masalah yang spesifik dan mendesak dari kehidupan fisik dan untuk melayani dunia simbolis, seni, politik, mitos, ritual, dan agama) (Postman, 1992). Contohnya adalah banyaknya petani yang menggunakan traktor pembajak sawah sekarang ini untuk mengefisiensi pekerjaanya dan menghemat tenaga, tidak seperti dulu dimana petani harus bekerja ektra keras dengan mengguunakan bintang kerbau untuk menggemburkan tanah di sawah. Teknologi terbentuk dan terus berinovasi untuk memenuhi kebutuhan dari manusia.

\section{Teori Kontruksi Sosial Teknologi}

Teori Kontruksi Sosial Teknologi atau Social Construction of Technology juga disebut dengan singkatan SCOT, berawal dari artikel dari Trevor Pinch and Wiebe Bijker's (1987) “The Social Construction of Facts and Artefacts: or How the Sociology of Science and the Sociology of Technology Might Benefit Each Other" (Klein \& Kleinman, 2014). Pinch dan Bijker mengonsepkan
Teori Konstruksi Sosial Teknologi yang bermula dari sepeda. Awal mula teknologi dan desain sepeda ditujukan kepada lelaki. Konstruksi sepeda itu pun kemudian mengalami perubahan ketika kaum wanita ingin juga bersepeda. Hal itu terjadi seiring gencarnya gerakan feminisme. Sehingga melahirkan sepeda yang secara desain ditujukan untuk wanita. Perubahan konsep desain sepeda adalah bentuk konstruksi suatu teknologi. Social Construction of Technology (SCOT) adalah teknologi dibentuk dari konstruksi sosial. Konstruksi sosial di dalam konsep ini dimaksudkan bahwa kehidupan sosial dalam masyarakat membentuk adanya sebuah teknologi. Teori SCOT ini menyatakan bahwa teknologi tidak menentukan tindakan manusia tetapi sebaliknya manusialah yang membentuk teknologi. Jika kita berbicara mengenai Determinasi Teknologi (Technology Determinism), maka teknologi yang membentuk kehidupan sosial, merupakan istilah yang pertama kali diciptakan oleh tokoh yang bernama Thornstein Veblen pada tahun 1920 yang menganggap bahwa teknologi adalah suatu kesatuan yang independen yang bersifat otonom. Segala tindakan dan kejadian yang dilakukan manusia akibat pengaruh perkembangan teknologi itu merupakan determinasi teknologi yang sebenarnya, karena tanpa disadari manusia sudah terpengaruh segala sesuatu yang dibawa oleh teknologi. Teknologi membentuk individu bagaimana cara berfikir, berperilaku dalam masyarakat dan teknologi tersebut akhirnya mengarahkan manusia untuk bergerak dari satu abad teknologi ke abad teknologi ke abad teknologi yang lain (McLuhan, 1994). Dengan kata lain, teknologi adalah sebab utama terjadinya perubahan masyarakat dan teknologi dipandang sebagai pembentuk struktur organisasi dan masyarakat. Konstruksi Sosial Teknologi (SCOT) berpendapat 
bahwa tindakan manusia membentuk teknologi (Yousefikhah, 2017).

JaditeoriSCOTmemilikipandangan yang bertolak belakang dengan teori Technology Determinism. Perbedaan keduanya terlihat dari siapa yang terpengaruh atau terbentuk. Dimana jika Technology Determinism, maka teknologi yang membentuk kehidupan sosial, namun menurut teori SCOT masyarakatlah yang membentuk teknologi atau masyarakat yang mempengaruhi perkembangan teknologi. Konsep dasar SCOT menyatakan bahwa desain teknologi merupakan suatu proses terbuka dimana kondisi sosial selama tahap pengembangan memiliki peran dalam menentukan desain akhir. Kondisi sosial yang berbeda-beda selama proses pengembangan desain berpeluang menghasilkan desain akhir yang berbedabeda pula (Klein \& Kleinman, 2014).

Dalam Social Construction of Technology (SCOT), kerangka kerja konseptual SCOT ini terdiri dari 4 komponen terkait yaitu : Interpretive flexibility (fleksibilitas interpretatif), The relevant social group (hubungan relevan dengan kelompok sosial), Closure and stabilization (keberakhiran dan stabilisasi), The wider context (konteks yang lebih luas) (Klein \& Kleinman, 2014).

Komponen pertama adalah fleksibilitas interpretatif. Konsep ini diambil dari program empiris relativisme dalam ilmu sosial dari ilmu pengetahuan, menunjukan bahwa desain teknologi merupakan proses terbuka sehingga dapat menghasilkan hasil yang berbeda tergantung pada keadaan sosial dari proses membangun teknologi itu sendiri. Pemaknaan bebas memperlihatkan bagaimana sebuah artefak yang sama setelah melalui kebutuhan suatu kelompok menjadikan artefak itu memiliki beberapa desain yang berbeda. (Klein \& Kleinman, 2014).
Konsep kelompok sosial yang relevan adalah komponen kedua dari kerangka SCOT. Menurut Pitch dan Bijker (dalam Klein \& Kleinman, 2014) Kelompok sosial yang relevan adalah perwujudan dari interpretasi tertentu : "semua anggota kelompok sosial tertentu berbagi set makna yang sama, melekat pada artefak tertentu". Mereka adalah agen dalam pendekatan yang berpusat pada agensi yang tindakannya memanifestasikan makna yang mereka berikan kepada artefak. Pengembangan teknologi adalah suatu proses di mana banyak kelompok, masing-masing mewujudkan interpretasi khusus dari suatu artefak, bernegosiasi atas desainnya, dengan kelompok sosial yang berbeda melihat dan membangun objek yang sangat berbeda. Sebagai contoh, kelompok mungkin memiliki definisi yang berbeda dari teknologi yang berjalan, sehingga pengembangan berlanjut sampai semua kelompok mencapai konsensus bahwa artefak umum mereka berfungsi. Desain berhenti bukan karena artefak bekerja dalam arti yang obyektif tetapi karena himpunan kelompok sosial yang relevan menerima bahwa ia bekerja untuk mereka (Bijker, 1995). Jadi pengertian relevansi disini, terjadi ketika pada kelompok lainnya mewujudkan interpretasi berbeda pada artefak yang sama, proses negosiasi atas desainpun terjadi. Pada setiap artefak yang digunakan oleh tiap kelompok akan mengandung makna dan arti tersendiri setelah bernegosiasi dengan makna artefak dari kelompok lainnya.

Komponen ketiga dari kerangka SCOT adalah penutupan dan stabilisasi. Penciptaan desain antar kelompok yang berbeda dapat mengalami kontroversi dalam hal interpretasi gambaran mengenai artefak teknologi. Konflik tersebut dapat selesai ketika desain artefak tidak lagi menimbulkan masalah kepada setiap kelompok sosial yang relevan. Hal ini terjadi saat proses interpretatif multi grup 
mencapai kesepakatan sehingga tidak terjadi modifikasi desain lebih lanjut, dan artefak teknologi mencapai bentuk akhirnya yang stabil (Klein \& Kleinman, 2014).

Komponen keempat, adalah adanya konteks yang lebih luas dari konstruksi sosial teknologi, memiliki kaitan dengan aspek sosial, budaya dan politik dimana pembangunan artefak itu berlangsung. Ini memainkan peran kecil dalam konsep asli SCOT Pinch and Bijker. Kondisi latar belakang dari interaksi-interaksi kelompok, seperti peran utama mereka, aturan-aturan yang mengatur interaksi mereka, dan faktorfaktor yang berkontribusi terhadap perbedaan kekuatan mereka (Klein \& Kleinman, 2014). Jadi Kelompok sosial memiliki cara pandang berbeda dalam menjalankan nilai sosial, budaya dan politik.

\section{Kontruksi Sosial Teknologi dalam Media Baru}

Berbicara mengenai media baru, internet atau teknologi digital telah merubah cara masyarakat berinteraksi dengan media. Kemajuan teknologi menglahirkan media baru atau lebih dikenal dengan istilah "new media". Media baru (new media) adalah istilah yang dimaksudkan untuk mencakup kemunculan digital, komputer, atau jaringan teknologi informasi dan komunikasi di akhir abad ke-20. Karakteristik dari media baru adalah dapat diubah (edit), bersifat jaringan, padat, interaktif dan bersifat user generated content. User-generated content adalah konten atau isi artikel dalam internet yang ditulis oleh khalayak umum, menandakan bahwa konten media internet tidak lagi hanya dapat dimonopoli oleh pihak berkepentingan namun dapat diunggah oleh semua internet user (Solomon, 2011).

Istilah new media (media baru) diperkenalkan salah satunya oleh McLuhan. new media yang dimaksud adalah perkembangan teknologi komunikasi yang dalam sejarahnya telah memperluas jangkauan komunikasi manusia (Salaz, Hodson, \& Davey, 2010). Disisi lain Mcluhan menggunakan istilah media new media untuk mendefinisikan sesuatu yang sangat mirip dengan apa yang dimaksud dengan new media saat ini. Seperti perkembangan teknologi komunikasi baru menghasilkan efek budaya yang kuat, jadi kehadiran new media menghasilkan model komunikasi massa baru dimana sebelumnya one to many communication menjadi many to many communication. Jadi new media mempunyai sifat yang interaktif dan bebas. Interaktif yang artinya interaksi terhadap khalayak langsung media yang mereka konsumsi. Sifat bebas yang dimaksud adalah khalayak dapat dengan bebas membuat konten-konten media yang mengandung informasi. Khalayak memegang kendali terhadap pendistribusian serta konsumsi konten dalam new media. Media baru menawarkan kemungkinan terjadinya pergeseran keseimbangan kekuasaan dari pengirim ke penerima, sehingga para pemakai dan pemilih dapat memperoleh beranekaragam pilihan isi, tanpa harus tergantung pada sistem mediasi dan pengendalian komunikasi massa (McQuail, 1994).

Media baru terkait dengan perkembangan teknologi informasi dan komunikasi, dikonstruksi dalam bentuk media digital merupakan terminologi yang mencakup seluruh peralatan teknis untuk memproses, menyimpan dan menyampaikan informasi. Artinya, teknologi informasi dan komunikasi ini berkaitan dengan berbagai hal proses, penggunaan sebagi alat bantu, manupulasi, dan pengolahan informasi. Media digital berkaitan dengan penggunaan alat bantu untuk memproses dan mentransfer data 
dari perangkat satu ke perangkat lainnya. (Arianto.S, 2016) . Menurut Hariyanto (dalam Arianto.S, 2016) kehadiran media digital ini dapat memudahkan manusia dalam pekerjaannya. Meski pada bagian lain dapat dipahami pula bahwa media baru berjaring internet dapat berdampak positif dan negatif bagi penggunaannya.

Menurut Bungin bahwa dalam dunia sosial, manusia menciptakan realitas sosial, karena manusia merupakan aktor yang kreatif dalam menciptakan realitas tersebut. Realitas sendiri muncul atas kekuatan konstruksi sosial terhadap lingkungannya (Bungin, 2014). Jika dikaitkan dengan perkembangan teknologi saat ini adalah, manusia menciptakan realitas teknologi menjadi sedemikian rupa atas konstruksi yang dipandangannya terhadap dunia sosial di sekelilingnya. Sehingga teknologi itu menjadi apa sesuai realitas yang diciptakannya. Sebagai contoh : Dalam hidup bermasyarakat sekarang ini dan perkembangan teknologi tidak ada istilah sulit untuk mendapatkan informasi atau manusiatidakdapatdi" "reach"(dijangkau), kemajuan teknologi terutama komunikasi membuat semua informasi mudah diakses dan setiap orang dapat berkomunikasi tanpa batas ruang dan waktu. Masyarakat mengkontruksikan bahwa dengan teknologi ini mempersempit batasanbatasan manusia dalam berkomunikasi dan mendapatkan informasi.

Media baru muncul sebagai hasil dari kontruksi sosial masyarakat dalam memanfaatkan perkembangan kemajuan teknologi informasi yang begitu pesat di era digital ini. Masyarakat sekarang ini membutuhkan sesuatu yang sifatnya instan, dan praktis dalam menunujang kehidupan mereka. Munculnya aplikasiaplikasi online atau mobile application hadir diciptakan untuk mengatasi permasalahan-permasalahan yang ada dalam masyarakat. Perspektif SCOT fokus pada bagaimana teknologi muncul akibat proses sosial. social constructivism adalah bagaimana dorongan sosial memengaruhi penemuan teknologi baru. Tidak hanya penemuan teknologi baru, social constructivism juga memaksa teknologi yang ada terus berinovasi untuk memenuhi tuntutan dari user dalam hal ini masyarakat. Sebagai contoh trend vlog (videoblog) sedang ramai di kalangan masyarakat pengguna media baru, aplikasi seperti WhatsApp , Facebook , Instagram, sebagai aplikasi media sosial melakukan inovasi dengan menambarkan video dalam fitur aplikasinya, yang dikenal dengan "Instastory", "My Status" video di WhatsApp dan "Facebook Stories". Para pembuat aplikasi atau content aplikasi harus dapat menangkap apa yang diinginkan atau disukai oleh user-nya, agar aplikasi tersebut tetap eksis dan tidak ditinggalkan oleh user nya.

\section{METODE}

Metode peneltian yang digunakan dalam penelitian ini adalah metode penelitian kajian pustaka atau studi kepustakaan (library research). Metode penelitian kepustakaan ini digunakan untuk menyusun konsep mengenai kontruksi sosial dalam teknologi dan media baru dan untuk mengetahui bagaimana peranan konsep kontruksi sosial dalam teknologi (SCOT) ini terhadap perkembangan teknologi media baru yang ada ditengah kehidupan masyarakat Indonesia atau melihat implementasi dari teori ini sebagai masalah dalam penelitian ini.

Dalam kajian pustaka, pengkajian mengenai konsep dan teori yang digunakan berdasarkan literatur yang tersedia, terutama artikel-artikel yang dipublikasikan dalam berbagai jurnal ilmiah. Kajian pustaka berfungsi untuk membangun konsep atau teori yang menjadi dasar studi dalam penelitian (Sujarweni, 2014). Kajian pustaka atau studi pustaka merupakan kegiatan yang 
diwajibkan dalam penelitian, khususnya penelitian akademik yang tujuan utamanya adalah mengembangkan aspek teoritis maupun aspek manfaat praktis (Sukardi, 2013).

\section{PEMBAHASAN}

Sejak kehadiran teknologi internet telah mempengaruhi sendi-sendi interaksi masyarakat dunia pada umumnya dan masyarakat Indonesia khususnya, tidak hanya seputar industri media massa konvensional atau traditional media melakukan konvergensi media menjadi industri media online dan di industri bidang perdagangan dimana berkembang sangat pesat industri belanja online, namun kini setiap kebutuhan manusia dari berbagai aspek juga dikembangkan aplikasi (media baru) berupa layanan aplikasi digital online. Berbagai macam aplikasi tersebut tersaji dalam smartphone atau gadget yang merangkum banyak kemudahan bagi individu-individu dalam menjalankan rutinitas kesehariannya termasuk industri transportasi berbasis online.

Kemunculan aplikasi transportasi online ini di Indonesia membawa perubahaan yang luar biasa bagi kehidupan sosial dan budaya masyarakat khususnya kota-kota besar. Salah satu jasa transportasi via mobile application adalah Go-Jek. Berbicara mengenai Go-Jek tidak akan terlepas dari sosok Nadiem Kariem sebagai founder dari GoJek, sebagai starup dibidang transportasi online sejak tahun 2011, Go-Jek dapat dikatakan fenomenal dan sukses. Go-Jek lahir dari ide Nadiem Kariem sebagai founder sekaligus waktu itu sebagai CEO dan Managing director dari GoJek, Kemacetan kota Jakarta yang luar biasa melatarbelakangi diciptakan aplikasi Go-Jek. Go-Jek sengaja dibuat untuk membantu masyarakat menebus kemacetan kota Jakarta yang sangat merugikan baik dalam hal waktu, tenaga, maupun secara ekonomi.

Kehadiran Go-Jek langsung mendapat respon postif dari masyarakat, dimana masyarakat khususnya kota Jakarta pada waktu itu membutuhkan transportasi yang cepat, aman, pasti dan terjangkau dari segi harga. Go-Jek ini memberikan dampak mengubah kebiasaan dan sistem sosial di dalam masyarakat. Awalnya, masyarakat hanya menggunakan cara konvensional untuk menggunakan transportasi umum, saat ini masyarakat mulai mengubah kebiasaan mereka dan beralih ke teknologi komunikasi untuk memesan transportasi umum secara online melalui smartphone mereka. Selain itu dengan adanya transportasi ojek online ini yang dilengkapi dengan sistem keamanan yang terjamin dan adanya seragam pada pakaian dan helmnya membuat citra pengemudi ojek yang dulunya dinilai sebagai kerjaan rendahan, sekarang semaking meningkat prestise-nya. Adanya Aplikasi Go-Jek sebagai wadah yang memfasilitasi para pengemudi oje, ini bisa mengubah mindset masyarakat tentang pengemudi ojek yang sering dipandang sebelah mata sebagai profesi rendahan. Perubahan mindset pengemudi ojek sebagai pekerjaan rendahan terbukti dengan semakin banyaknya orang yang tertarik menjadi tukang ojek sebagai pekerjaan sampingan. atau bahkan menjadi pekerjaan utama menjadi salah satu dampak positif dari hadirnya aplikasi transportasi online Go-Jek. Fenomena tranportasi online kini menyebar luas tidak hanya hadir di Jakarta tapi model transportasi online ini dibawa Go-Jek ke kota-kota besar lainnya di Indonesia, seperti : Surabaya, Semarang, Yogyakarta, Bali, dan kota-kota lainnya. Go-Jek pun tidak bergerak secara monopoli dalam bisnis transportasi online, dimana bermunculan perusahaan kompetitor transportasi online seperti Grab, dan dahulu ada Uber untuk merebut pangsa 
pasar.

Dilihat dari perspektif teori SCOT (Social Construction of Technology) kemunculan teknologi aplikasi transportasi berbasis online seperti Gojek, dahulu sebelum adanya teknologi aplikasi transportasi berbasis online, pilihan transportasi yang tersedia di antaranya adalah ojek, bis umum, angkot atau taksi konvensional. Seringkali pilihan transportasi konvensional yang ada tidak dapat sepenuhnya diandalkan oleh masyarakat khusus masyarakat perkotaan yang memiliki mobalitis yang tinggi, pilihan transportasi umum konvensional memiliki beragam faktor minus, seperti ketidakpastian lokasi transportasi harus berjalan mencari halte, terminal, pangkalan ojek atau taksi terlebih dahulu, ketidakpastian waktu berangkat, keamanan dan kenyamanan yang kurang. Konteks sosial seperti inilah yang mendorong para inventor untuk berinovasi menemukan dan mengembangkan teknologi baru untuk memenuhi demand yang ada terhadap pilihan transportasi yang lebih efektif. Sehingga disini dapat terlihat bahwa para inventor dari aplikasi transportasi berbasis online merupakan manusia yang berperan sebagai agent of change dan pemikirannya dipengaruhi oleh konteks sosial yang sedang ada di masyarakat saat ini. Para inventor ini juga memiliki prioritas-prioritas untuk menentukan apa lagi yang perlu dikembangkan atau melakukan inovasi dari teknologi yang sudah ciptakan, misalnya dalam aplikasi tranportasi online Go-Jek ini terus berinovasi menghasilkan teknologi baru untuk memenuhi kebutuhan dari masyarakat.

Go-Jek sebagaimana yang kita ketahui tidak hanya menyediakan jasa transportasi , tapi Go-Jek berhasil menambahkan berbagai fitur baru yang berusaha memenuhi kebutuhan masyarakat via teknologi aplikasi digital, salah satu fitur lain paling sukses dari GoJek adalah Go-Food yaitu jasa pembelian dan pengantaran makanan, Inventor apalikasi Go-Jek menangkap peluang bahwa masyarakat perkotaan ditengah kesibukan yang tinggi pasti memiliki waktu terbatas, Go-Food hadir untuk membantu mereka untuk memenuhi kebutuhan pembelian makan, dimana makan termasuk kebutuhan primer pasti tingkat kebutuhan dari masyarakat juga tinggi dimana hal ini bagus dilihat dari segi bisnis. Dengan hadirnya Go-Food ditengah masyrakat ini sangat membantu, konsumen bisa memesan makanan secara online dan melakukan hal lain sembari menunggu pesanan mereka datang, GoFood tidak hanya membantu konsumenya tapi juga Pedagang dimana dengan teknologi ini jualan makanan mereka bisa menjangkau atau dinikmati oleh konsumen dari berbagai lokasi sehingga otomatis membantu pendapatan dari para penjual makanan yang ber-partnership dengan Go-Food.

\section{SIMPULAN}

Media baru muncul sebagai hasil dari kontruksi sosial masyarakat dalam memanfaatkan perkembangan kemajuan teknologi informasi yang begitu pesat di era digital ini. Masyarakat sekarang ini membutuhkan sesuatu yang sifatnya instan, dan praktis dalam menunujang kehidupan mereka. Munculnya aplikasiaplikasi online atau mobile application hadir diciptakan untuk mengatasi permasalahan-permasalahan yang ada dalam masyarakat, seperti Go-Jek. Berbicara mengenai SCOT adalah teori yang memiliki perspektif bahwa teknologi tidak menentukan manusia sebagaimana pandangan dari teori determinasi teknologi, tapi manusia-lah yang mengatur tindakan dari teknologi itu sendiri.

Social Construction of Technology ( (SCOT) adalah fokus pada bagaimana 
teknologi muncul akibat dari proses sosial. Social constructivism adalah bagaimana dorongan sosial memengaruhi penemuan teknologi baru. Tidak hanya penemuan teknologi baru, social constructivism juga memaksa teknologi yang ada terus berinovasi untuk memenuhi tuntutan dari user dalam hal ini masyarakat. Sebagaimana yang dilakukan Go-Jek yang terus berinovasi dengan menghadirkan Go-Food, dan fitur-fitur lainnya.

\section{DAFTAR PUSTAKA}

Arianto.S. (2016). Penggunaan Media Baru Di Komunitas Petani \& Nelayan. Jakarta : Puslitbang Aptika IKP, Badan Penelitian dan Pengembangan Sumber Daya Manusia Kementerian Komunikasi dan Informatika RI.

Bijker, Wiebe. (1995). Of bicycles, bakelites, and bulbs: Toward a theory of sociotechnical change. Cambridge, MA: MIT Press.

Bijker, Wiebe E. dan Pinch, Trevor J. (1987). The Social Construction of Technological System : New Direction in The Sociology and History of Technology.

Bungin, M. Burhan. (2014). Sosiologi Komunikasi, Teori, Paradigma dan Diskursus Teknologi Komunikasi di Masyarakat. Jakarta: Kencana Prenadamedia Group

Gojek Indonesia, https://www.go-jek.com/ about/ (Di akses pada tanggal 30 April 2018)
Jogiyanto, HM. (2001). Pengertian Aplikasi dan perkembangannya. Yogyakarta: Andi Ofset.

Klein, H. K., \& Kleinman, D. L. (2014). The Social Construction of Technology : Structural Considerations, 27(1), 2852.

McLuhan, Marshall. (1994). Understanding Media: The Extension of Man. London: The MIT Press.

McQuail, Denis. (1994). Teori Komunikasi Massa, Edisi Kedua. (diterjemahkan oleh: Agus Dharma dan Aminuddin Ram). Jakarta: Erlangga.

Postman, Neil. (1992). Technopoly The Surrendeer of Culture to Technology. United State: Vintage Books.

Salaz, K., Hodson, T., \& Davey, C. J. (2010). New Media and the Courts: The Current Status and a Look at the Future. Papers.Ssrn.Com. Retrieved from http://papers.ssrn.com/sol3/ papers.cfm?abstract_id $=1666332$

Solomon, Michael R dan Tracy L. Tuten. (2011) Social Media Marketing. UK: SAGE.

Sujarweni, V.Wiratna. (2014). Metodelogi Peneltian. Yogyakarta : Pustaka Baru

Sukardi. (2013). Metodelogi Penelitian Pendidikan Kompetensi dan Praktiknya. Jakarta : PT.Bumi Aksara

Yousefikhah, S. (2017). Sociology of innovation: Social construction of technology perspective. $A D$ Minister, (june), 31-43. https://doi. org/10.17230/ad-minister.30.2 